\title{
Of German princes and North American rivers: Harlan's lost mosasaur snout rediscovered
}

\section{M.W. Caldwell ${ }^{1, *}$ \& G.L. Bell Jr. ${ }^{2}$}

1 University of Alberta, Department of Earth and Atmospheric Sciences, and Department of Biological Sciences, Edmonton, Alberta, Canada T6G 2E9.

2 Guadalupe Mountains National Park, HC 60-\#309, Salt Flat, Texas 79847, USA.

* Corresponding author. Email: mw.caldwell@ualberta.ca

Manuscript received: January 2005; accepted: March 2005

\begin{abstract}
The lost snout of Richard Harlan's specimen of Mosasaurus missouriensis has been rediscovered in the vertebrate palaeontology collections of the Muséum national d'Histoire Naturelle (MNHN) in Paris, France. The specimen (MNHN 9587) bears the handwritten description, 'Amérique du Nord. Par M. Harlan.', which translated reads, 'North America. By/From Mr. Harlan'. Accession information indicates the specimen was a gift to the museum prior to 1860 and was likely gifted from Harlan's estate after his death. We examine the available history of the collection of the specimen present a description of the rediscovered snout, and demonstrate conclusively the conspecificity of M. maximiliani Goldfuss, 1845 and M. missouriensis (Harlan, 1834a) by providing a revised diagnosis of the taxon.
\end{abstract}

Keywords: Mosasauridae, Missouri, taxonomy, systematics, synonymy

\section{Introduction}

In 1832, Richard Harlan read an interesting and important little paper entitled, 'Notice of the discovery of the remains of the Ichthyosaurus in Missouri, N.A.' He gave his species of 'ichthyosaur', as he had identified the material, the specific epithet of missouriensis. The specimen so assigned to this new species was the anterior portion of a premaxilla and the anteriormost portions of the right and left maxillae of a mosasaur.

Harlan subsequently published this presentation (Harlan, 1834a) and included in that paper illustrations of his 'ichthyosaur' specimen (Fig. 1A - D). As he writes (Harlan, 1834a, p. 405), the snout fragment came to him from '... Major N.A. Ware, who obtained it from a trader, with the information contained in the following label: 'A trader from the Rocky mountains, on his return, near the Yellow-stone knobs, or hills, observed, in a rock, the skeleton of an alligator-animal, about seventy feet in length; he broke off the point of the jaw as it projected, and gave it to me. He said that the head part appeared to be about three or four feet long'.

At roughly the same time as Harlan was studying his snout fragment, Prince Maximilian zu Wied was traversing the American West (1832-34), the tale of which was subsequently published in his memoirs (Wied, 1840-41). While in St. Louis, the Prince purchased a very well-preserved mosasaur skull and skeleton that was on display in the garden of one Major 0 'Fallon, former Agent of the Indian Nations of the Upper Missouri. According to Goldfuss (1845), O'Fallon collected the specimen between Ft. Lookout and Ft. Pierre near the Big Bend of the Missouri River and brought it back his garden in St. Louis. Once back in Germany, zu Wied presented his fossil to Professor August Goldfuss, who, in 1842, presented a paper detailing his description of the skull and jaws to the geological section of the Natural Scientists Conference at Mainz; it was published three years later (Goldfuss, 1845). 


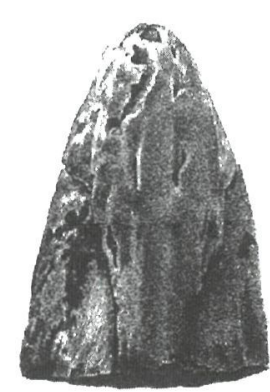

A

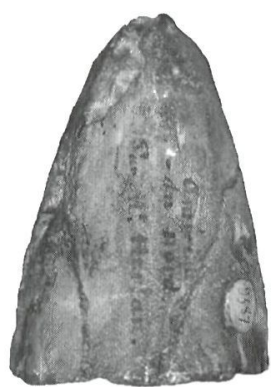

E

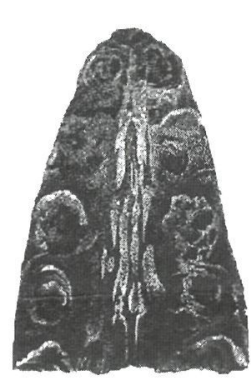

$B$

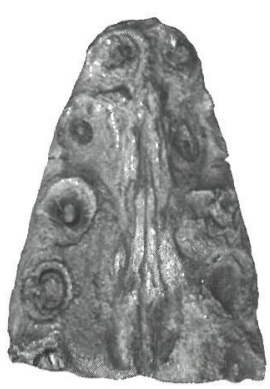

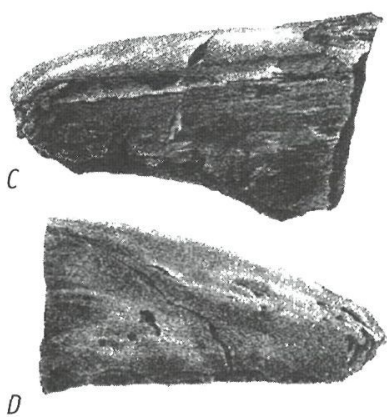

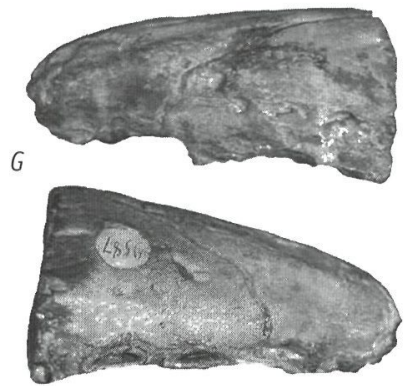

$10 \mathrm{~cm}$

Fig. 1. Original illustrations of Richard Harlan's (1834a) 'Ichthyosaurus missouriensis' ( $A$ - D) with photographs of the recently re-discovered specimen, MNHN $9587(E-H)$; $A$ - dorsal view; $B$ - ventral view; $C$ - left lateral; and $D$ - right lateral views (all modified from Harlan, 1834a, pl. 20). E-dorsal; $F$ - ventral; $G$ - left lateral; $H$ - right lateral views, respectively (Note the handwritten script on the dorsal surface of the premaxillary tip. 'Amérique du Nord. Par M. Harlan.').

At roughly the same time, von Meyer (1845) noted that the snout tip described by Harlan (1834a) may well have been the missing premaxillary-maxillary portions of Goldfuss's (1845) mosasaur skull. This idea was subsequently articulated by Cope (1875), Camp (1942) and finally by Russell (1967).

The possibility that $\mathrm{zu}$ Wied and Harlan had happened upon matching portions of the same specimen was interesting for its serendipity, but it was also important in terms of taxonomy. Although Harlan's (1834a) description erred in referring missouriensis to the genus Ichthyosaurus, and thus to a non-squamate group of diapsid reptiles, his specific epithet had priority over Goldfuss's (1845) accurate characterisation of his specimen as a mosasaur, bearing the name Mosasaurus maximiliani. The solution to this problem of senior vs junior synonyms should have been easily achieved after 1845 but for one small problem, Richard Harlan had died in 1843 and no one was able to locate his specimen of 'Ichthyosaurus missouriensis'.

As is now clear, there are several historical clues that bear on the mysterious disappearance of Harlan's mosasaur snout. In 1833, Harlan had undertaken his first great tour of Europe (http://www.amphilsoc.org/library/mole/h/harlan.htm). As a physician and naturalist, he made sure to visit both medical and natural science institutions, most notably spending a great deal of time in Paris, frequently calling upon the recently widowed Madame Cuvier. He was obviously impressed by the impact of Baron Cuvier to the point that he named his son, born in 1835, George Cuvier Harlan. In 1839, after six years in Philadelphia, Richard Harlan returned to France with the intention of remaining for an extended period of time. However, his visit was cut short when his scientific collections in Philadelphia were destroyed in a fire. It is possible that the snout of his mosasaur was among the specimens in that collection. He returned to Philadelphia, salvaged his collections and, in 1842, moved to New Orleans where he resided until his death in 1843 (http://www.amphilsoc.org/library/mole/h/ harlan.htm). At this point in time, any knowledge of the location of what we refer to here as Harlan's Lost Snout, is lost.

In the present paper, we add to the history of Richard Harlan's mosasaur snout by reporting on our rediscovery of this specimen in the vertebrate palaeontology collections of the Muséum national d'Histoire Naturelle (MNHN) at Paris (Fig. 1E - H); the specimen (MNHN 9587) now bears the handwritten description, 'Amérique du Nord. Par M. Harlan.' (Fig. 1E), which translates as, 'North America. By/From Mr. Harlan'. The the specimen label reads, 'Bout de museau donné comme provenant d'un saurien. Amérique par Mr. Harlan. VI - 1314.', which roughly translates as, 'End of a given muzzle like that of a lizard.' With the assistance of Dr D. Goujet, we located the accession information indicating the specimen was a gift to the museum prior to 1860; this date is all the information contained in MNHM archives as it represents the point in time when the old collections of Cuvier and others, were transferred to the 'new' museum post-1860. At this point we do not know if the specimen made its way to Paris with Harlan in 1839 (http://www.amphilsoc.org/library/mole/h/harlan.htm), or if it was donated by him prior to his death but after his European trip, or after his death by his estate executors.

Here we present our description of the rediscovered snout (MNHN 9587) with a comparison made using the cast of the specimen to a cast of the broken portion of the snout of Goldfuss's Mosasaurus maximiliani (Fig. 2), the latter of which is housed in collections of the Institut für Paläontologie, Rheinische Friedrich-Wilhelms-Universität (Bonn; RFWUIP) 


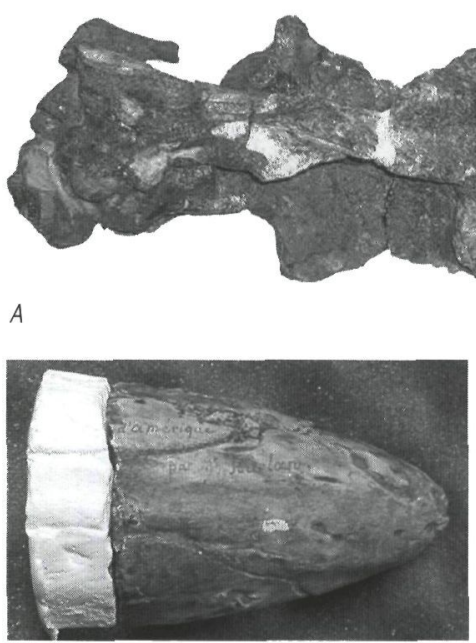

B

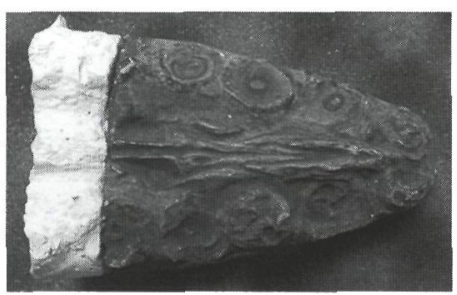

Fig. 2. Photomosaic of a ventral view of the skull of $z u$ Wied's specimen (A) of Mosasaurus missouriensis (= maximiliani) (RFWUIP 1327) and Harlan's snout (MNHN 9587) (photo of RFWUIP 1327 courtesy of Olivier Wings), dorsal view (B) of cast of MNHN 9587 and cast of snout tip of RFWUIP 1327, and ventral view (C) of cast of MNHN 9587 and cast of snout tip of RFWUIP 1327. Note that the cast bears handwritten script as does the holotype specimen.

bearing number RFWUIP 1327. Further, we demonstrate the conspecificity of $M$. maximiliani Goldfuss, 1845 and M. missouriensis (Harlan, 1834a) by providing a revised diagnosis of the taxon.

\section{Systematic palaeontology}

Order Squamata

Family Mosasauridae

Subfamily Mosasaurinae

Genus Mosasaurus Conybeare, 1822

Type species - Mosasaurus hoffmani Mantell, 1829

\section{Mosasaurus missouriensis (Harlan, 1834a); Figs 1 - 3}

1834a Ichthyosaurus missouriensis Harlan, p. 408.

1834b Ictiosaurus missuriensis Harlan, p. 124.

1839a Batrachiosaurus missouriensis; Harlan, p. 24.

1839b Batrachiotherium missouriensis; Harlan, p. 89.

1845 Mosasaurus maximiliani Goldfuss, p. 179.

1845 Mosasaurus neovidii von Meyer, p. 312.

1858 Mosasaurus missouriensis; Leidy, p. 90.

1882 Pterycollosaurus maximiliani; Dollo, p. 61.

1895 Mosasaurus horridus Williston, p. 166.

Type material - A very well-preserved skull and right and left lower jaws (RFWUIP 1327) and a snout tip (MNHN 9587).

Locality - From the Big Bend, Missouri River, southeast of Pierre, South Dakota (USA).

Diagnosis - A plotosaurine mosasaur with very small premaxillary predental; dorsally, premaxilla prismatically contoured, with five facets including central, flattened facet, dorsolateral pair of facets, and lateral pair; both dorsolateral and lateral pairs extend short distance onto maxillaries; posterior end of premaxillary internarial bar laterally expanded forming tridentate suture with anterior end of frontal; external nares beginning anteriorly above fourth maxillary tooth and extending posteriorly above eleventh maxillary tooth; 14 tooth positions in maxilla; frontal dorsal surface triangular, sides converging anteriorly as straight edges, anteriormost portion relatively wide and essentially parallel-sided; posterior frontal prongs deeply invading parietal and extending well posterior of parietal foramen; nine tooth positions in pterygoid with pterygoid tooth row ending posteriorly approximately even with middle of ectopterygoid process; marginal teeth distinctly facetted with carinae finely and uniformly serrated; a minimum of 11 pygal vertebrae.

Description - The anterior portion of the premaxilla (Fig. 1E - H) is well preserved with only some slight damage on the left side. Initial inspection suggests this might actually be a palaeopathology. The snout tip of the premaxilla is blunt and subrounded, and has an extremely small predental rostrum. The premaxillary sutures on both the right and left sides show slightly different sutural traces, but consistently show a steep dorsal rise in the first third, followed a gradual obtuse angle as the suture continues to run posteromedially. The premaxillary bar is therefore very robust in its anteriormost extent and does not show the constriction or 'waisted' appearance typical of other mosasaurs. In ventral view, the premaxilla shows four tooth positions, with the anteriormost pair being immediately on the anterior margin of the bone. The anteriormost pair of teeth are slightly smaller than the more posterior pair, and certainly about two-thirds the size of the anteriormost maxillary teeth (Fig. 1F). The vomerine processes of the premaxilla are well preserved, but not well prepared; it is therefore not possible to ascertain the position of the premaxillary foramina.

Only the anteriormost tips of the vomers (Fig. 1F) are preserved; they are not well prepared in the specimen, but are well preserved. They are paired, elongate elements, consistent with the morphology as described for other mosasaurines (Russell, 1967), and do show the presence of paired vomerine 
foramina (Fig. 1F). These foramina are even with second maxillary tooth position. Immediately posterior to this pair of foramina, the vomers appear to constrict medially. This constriction, though not well prepared, likely presents the vacuity created between the maxillae and vomers for the Jacobson's organ fenestra.

The right and left maxillary fragments are small, but approximately equal in size (Fig. 1E, F). Each preserves two complete and one fractured tooth positions; there are no complete teeth preserved, nor were there any present at the time of Harlan's (1834a) description (Fig. 1A - D). In lateral view, both the right and left maxilla facial nerve show the presence of a variable number of maxillary foramina (exit points for the maxillary nerve branches of the trigeminal nerve $(\mathrm{V})$ ).

\section{Discussion}

The discovery of Harlan's snout in the Paris collections settles one of the oldest taxonomic debates in the science of mosasaur palaeontology: Mosasaurus missouriensis (Harlan, 1834a) is indeed the senior synonym of Mosasaurus maximiliani Goldfuss, 1845. Mosasaur workers pondering this probability, from von Meyer (1845) to Russell (1967), were indeed right, despite the absence of the evidence. While we did not borrow the specimen in Paris and then travel to Bonn to perform the ultimate acid test, we did perform a slightly weaker version of the test. We borrowed a cast of the Harlan specimen (MNHN 9587) from Paris, and compared it to a cast of the snout tip (RFWUIP 1327) in the possession of one of us; the fit was and is perfect (Fig. 2A - C).

Future descriptive work on Goldfuss's specimen can now confidently refer the specimen to $M$. missouriensis, and then accurately characterise other locally and globally distributed mosasaurines against the features of both the Bonn (RFWUIP 1327) and Paris specimens (MNHN 9587). While unremarkable as a specimen, MNHN 9587 does complete Goldfuss's skull, and most interestingly, has a long and very intriguing history.

\section{Conclusions}

While Harlan's Lost Snout is small and of not much morphological value in terms of understanding Mosasaurus missouriensis as an animal, it is significant in terms of the history and taxonomy of North American mosasaurs relative to the problems it helps solve. In an as yet poorly understood twist of fates, both Richard Harlan and Maximilian zu Wied came to possess unequal-sized portions of the same individual mosasaur exposed along the banks of the Missouri River. For Prince Maximilian, his connection to the specimen was Major Benjamin 0'Fallon and the news in St. Louis that a fossil resided in 0'Fallon's garden; just how 0'Fallon obtained the specimen remains unknown. We can only conclude that he found and collected it himself. It is intriguing to consider that perhaps the fur- trader who passed the snout to Ware, which must have occurred prior to Harlan's presentation of his paper in 1832, was also the connection by which 0'Fallon became aware of the fossil. It is certainly true that $0^{\prime}$ Fallon must have possessed the skull, jaws and skeletal fragments sometime prior to the Prince's visit to St. Louis between 1832-34; this almost synchronises the collection of both the Lost Snout and the skull, jaws and skeleton to around 1830-31. Equally as intriguing is that neither Harlan, zu Wied, or Goldfuss, who all knew of each other's specimens, ever published an admission that they might have been in possession of two portions of the same specimen; this was left to a third party, von Meyer (1845), to suggest. Perhaps as a means of avoiding synonymy, both groups avoided what must have been as obvious to them as to anyone else. It is certainly true that Harlan knew of zu Wied's specimen as he noted (Harlan, 1835: p. 81) that, 'Baron Braunsberg Maximillian (sic) de Wied, during his recent visit to Philadelphia, on his return from the Rocky Mountains, informed me that he had obtained the fossil skeleton of a saurian animal, fifteen feet in length, from the 'great bend' of the Missouri River, which on comparison of its characters with those of the animal above (Harlan's Ichthyosaur) noticed, he thinks belongs to the same species.'

What deepened the mystery for von Meyer (1845) and all subsequent authors was the disappearance of Harlan's snout after his death in 1843. The fact that it was donated to the Muséum national d'Histoire naturelle (Paris) after Harlan died seems mysterious in the absence of an understanding of his fascination with Paris and his respect for Baron Georges Cuvier. Clearly, in Richard Harlan's mind, and likely that of his family, the place for his mosasaur was in Paris, in the same 'grande galerie' in which Cuvier's own giant marine lizard, now Mosasaurus hoffmanni Mantell, 1829, still resides. This has been truly a fascinating journey for the snout of one very ancient marine lizard - into the annals of scientific history at the beginning of the formative years of the discipline of mosasaur palaeontology.

\section{Acknowledgements}

We thank Bernard Battail for hosting us, and Daniel Goujet for his scholarly assistance while we visited collections at the Muséum national d'Histoire naturelle (Paris), and Martin Sander for making the cast of the snout of RFWUIP 1327 and for hosting the junior author during a visit to Bonn in 1992 to examine that specimen. We also thank Oliver Wings for permission to use one his photographs of RFWUIP 1327, and especially Mike Everhart for discussions on the historical aspects of this project, a first read of the manuscript and for the spectacular amount of background work he has done on this subject that therefore made our historical research rather easy. 


\section{References}

Camp, C.L., 1942. California mosasaurs. Memoirs of the University of California 13: vi $+1-67$.

Conybeare, W.D., 1822. In: J. Parkinson (ed.). An Introduction to the study of fossil organic remains. vii +344 pp., London.

Cope, E.D., 1875. The Vertebrata of the Cretaceous formations of the West. Report of the United States Geological Survey of the Territories 2: 302.

Dollo, L., 1882. Note sur l'ostéologie des Mosasauridæ (sic). Bulletin du Musée d'Histoire naturelle de Belgique 1: 55-80.

Goldfuss, A., 1845. Der Schädelbau des Mosasaurus, durch Beschreibung einer neuen Art dieser Gattung erläutert. Nova Acta Academiae Caesar LeopoldinoCarolinae Germanicae Natura Curiosorum 21: 173-200 (1-28).

Harlan, $\boldsymbol{R}_{\text {. }}$ 1834a. Notice of the discovery of the remains of the Ichthyosaurus in Missouri, N.A. Transactions of the American Philosophical Society 4: 405-409.

Harlan, R., 1834b. Announcement of the finding of Ichthyosaurus missouriensis and Basilosaurus. Bulletin de la Société géologique de France (1)4: 124.

Harlan, R., 1835. Critical notices of various organic remains hitherto discovered in North America. Transactions of the Geological Society of Pennsylvania 1(1): 46-112.

Harlan, R., 1839a. Notice of the discovery of Basilosaurus and Batrachotherium. Proceedings of the Geological Society of London 3: 23-24.

Harlan, R., 1839b. (Letter regarding Basilosaurus and Batrachotherium). Bulletin de la Société géologique de France (1)10: 89-90.

Leidy, J., 1858. (Remarks on Mosasaurus). Proceedings of the Academy of Natural Sciences Philadelphia 9: 176.

Mantell, G.A., 1829. A tabular arrangement of the organic remains of the county of Sussex. Transactions of the Geological Society (2)3: 201-216.

Russell, D.A., 1967. Systematics and morphology of American mosasaurs. Bulletin of the Peabody Museum of Natural History, Yale University 23: 1-241.

Von Meyer, H., 1845. (Letter to Professor Bronn). Neues Jahrbuch für Mineralogie, Geognosie und Geologie 1845: 308-313.

Williston, S.W., 1895. New or little known extinct vertebrates. Kansas University Quarterly 2: 83-84.

Zu Wied, M., 1840-41. Reise in das Innere Nord-Amerika in den Jahren 1832 bis 1834, 2 volumes. Verlag J. Holscher (Koblenz): 687 pp.

http://www.amphilsoc.org/library/mole/h/harlan.htm, Richard Harlan Journals, 1816-1817, 1833 (American Philosophical Society). 